\title{
Advantages of IT-based clinical pathways in surgical treatment of non-specific spondylodiscitis
}

\author{
N. Homagk ${ }^{1}$, T. Jarmuzek ${ }^{1}$, H.J. Meisel ${ }^{2}$, G.O. Hofmann ${ }^{3}$, L. Homagk ${ }^{* 1,4}$ \\ ${ }^{1}$ Centre for Spinal Cord Injuries, BG -Kliniken Bergmannstrost, Halle/Saale, Germany \\ ${ }^{2}$ Department of Neurosurgery, BG -Kliniken Bergmannstrost, Halle/Saale, Germany \\ ${ }^{3}$ Department of Trauma, Hand and Reconstructive Surgery, Friedrich Schiller University Jena, Germany \\ ${ }^{4}$ Department of Orthopaedic and Trauma, Asklepios Clinic Weißenfels, Germany
}

Received: May 17, 2016

DOI: $10.5430 /$ jha.v5n6p19
Accepted: August 18, 2016

Online Published: August 22, 2016

\begin{abstract}
Objective: The German health care system increasingly incorporates clinical pathways as a tool to organize surgical, intervention or conservative therapies. Does a computerized clinical pathway offer advantages in severity-based surgical therapy of spondylodiscitis?

Methods: A hospital has adopted a computerized system based on three severity grades of spondylodiscitis. From 01/01/2012 to $12 / 31 / 2013$, 32 patients with spondylodiscitis were randomly chosen at admission and prospectively analysed with regard to duration, costs of treatment, pain level and inflammatory markers.

Results: Of the 32 patients treated for spondylodiscitis who had not been transferred from another facility, 17 (53\%) were treated according to a clinical pathway based on three well-established treatment regimens dependent on severity. The SponDT, as a parameter for the course of disease, was initially slightly higher in the pathway patient's group (6.82) than in the control group (6.2). Compared to a control group $(n=15)$ there were differences in the total duration of stay (17.2 vs. 26.0) and the number of blood samples taken ( 7 vs. 10). No differences could be shown for the extent of documentation, the physical and neurological outcome, the level of pain and or the course of inflammatory markers. The most prevalent germ was Staphylococcus aureus (18.8\%). In $43.8 \%$ of the patients, no infectious agent could be detected. Material costs and personnel-costs were significantly reduced in the pathway group (12,076 $€$ ) compared to $21,341 €$ in the control group.

Conclusions: An IT-based clinical pathway is preferable for surgical therapy of spondylodiscitis based on three grades of severity and offers various advantages as a clinical and administrative regulative mechanism. The cost-effective treatment particularly stands out.
\end{abstract}

Key Words: Spondylodiscitis, Scoring system, Classification of severity, Clinical pathway

\section{INTRODUCTION}

Clinical pathways give a detailed description of necessary procedures in diagnostics and therapy, and hospitals are establishing them more and more frequently. ${ }^{[1,2]}$ This kind of process optimisation leads to better patient contentment and increases transparency and comparability of treatment. ${ }^{[3,4]}$
Furthermore, clinical pathways can prevent unnecessary procedures and can be used to optimize a budget. Clinical pathways are initiated upon admission of the patient and pursued until discharge. When developing a clinical pathway, internal work flow has to be analysed to determine criteria for inclusion/exclusion or for a necessary switch to an alter-

*Correspondence: L. Homagk; Email: info@ praxiklinik-naumburg.de; Address: Praxisklinik Naumburg, Markt 3, 06618 Naumburg, Germany. 
native pathway. Hence, a pathway is a tool which includes both occupational and work groups. ${ }^{[2]}$ Furthermore, they are useful for collecting and evaluating qualitative and economic data, which can be used for process optimisation. ${ }^{[5]}$ In our hospital of maximum care, information technology (IT)supported clinical pathways have been established since 2009 for numerous surgical, traumatological and endoprothetic treatments, with a focus on optimising processes and documentation. ${ }^{[6]}$

Spondylodiscitis, an infectious disease of the vertebral bodies, intervertebral discs and adjacent structures, occurs in one out of 125,000 people, and three times more often in men than in women. The spectrum of the infectious agent is broad, but there is a predominance of Staphylococcus aureus. ${ }^{[7-9]}$ In our own group of patients the peakage was beyond the sixth decade of life. Risk factors include, inter alia, higher age, Diabetes, malnutrition, consuming disease, steroid therapy, immunosuppression, rheumatoid diseases, drug abuse and surgical procedures of the spine. The mortality rate is currently below 5\%. ${ }^{[7-9]}$ The pathogenesis of spondylodiscitis is mainly via haematogenous spread, direct inoculation of pathogenic microorganisms during surgery or via continuous spread from an infection of the surrounding soft tissues. The spontaneous spondylodiscitis is caused by haematogenous spread. The main localization of spondylodiscitis is the lumbar spine $(60 \%)$, followed by the thoracic spine $(30 \%)$ and cervical spine $(10 \%){ }^{[10-12]}$

Spondylodiscitis usually presents unspecific symptoms such as malaise, low fever, fatigue, varied back pain and weight loss. This causes a delay in finding the correct diagnosis of up to several months. ${ }^{[9,11]}$ Besides taking the past and present medical history, initial diagnostic tools are physical and neurological examination, taking the temperature and blood analysis, followed by diagnostic imaging. Often the exact diagnosis is only possible with the help of a histological examination and the direct verification of the infectious agent. ${ }^{[7,13]}$ When there is a compression of the spinal cord with neurological symptoms and in case of destructive lesions with imminent spinal instability or abscess formation the treatment should be surgical. ${ }^{[14,15]}$ The aim of surgery should be the radical and complete debridement of the whole infectious and necrotic area and to restore the stability of the spine. Depending on the size of the defect, eligible materials for repair are mono- or bicortical pelvic bone grafts or autologous fibula or now more frequently foreign implants like titan cages. ${ }^{[8,9,15]}$ Minimally invasive methods are increasingly put into practice. ${ }^{[16-18]}$

The aim of this study was to show an improvement of treatment quality and documentation by translating the severity- based treatment of spondylodiscitis into an IT-based clinical pathway, which determines treatment algorithms and allows respective evaluation including economic aspects.

\section{Materials AND METHODS}

In our institution about 13,500 inpatients are treated per year. When developing a clinical pathway for the severity-adapted therapy of spondylodiscitis, we could revert to existing ITroutines. All relevant treatment components, starting on admission with medical history and evaluation of risk factors, then diagnostic measures, surgery and aftercare are implemented in the pathway, also called a planning sheet. ${ }^{[19]}$ Medical guidelines and internal standards provide the basic concept. Following the development of the planning sheet, every single process is reviewed and verified by all occupational groups involved for a general consensus. The spondylodiscitis pathway was electronically translated into the IT-system, which allows intern workstations data-protected access. ${ }^{[6]}$

The practical application of the clinical pathway starts with admission of the patient. It then shows which work steps are completed and which are still to be carried out by whom (see Figure 1). The implementation of the randomization was done during the admission process. Further therapy with or without pathway was carried out in different departments.

The main users are physicians and nurses. But staff members of other professions such as physiotherapy, anaesthesiology, radiology and social service have access to the pathway as well. All treatment steps with the corresponding measures, information and forms are available for the authorized staff. Thus, the following procedures can be used within the pathway:

- taking medical history

- automatic registration for all necessary procedures (e.g. $X$-ray, laboratory testing, Electrocardiograph [ECG], surgery, physiotherapy)

- automatic generation of directions and consultations (e.g. medication, auxiliaries, food orders)

- integration of all results into the patients electronic file

- automatic generation of the patients medical record

- documentation for quality assurance

- documentation of daily round and pain level

Further relevant data for all these procedures are available as well. ${ }^{[6]}$ The documentation of pain level is also included within the hospitals IT-system based on the numeric rating scale (NRS), ranking from $0=$ no pain to $10=$ worst pain imaginable. ${ }^{[19]}$ The cost-analysis used in this study compares the treatment with and without pathways assuming an equivalent medical outcome. ${ }^{[20]}$ For the compared groups 
all costs are recorded regarding cost centre and cost element. therefore non-monetary) values. Additionally, the SponDT This is followed by a cost-effectiveness analysis. ${ }^{[21]}$ The was developed as a course monitoring tool. ${ }^{[15]}$ It summaadvantage of the pathway treatment is also described by us- rizes the clinical, paraclinical and morphological extend of ing additional criteria, which are defined in medical (and spondylodiscitis (see Table 1).

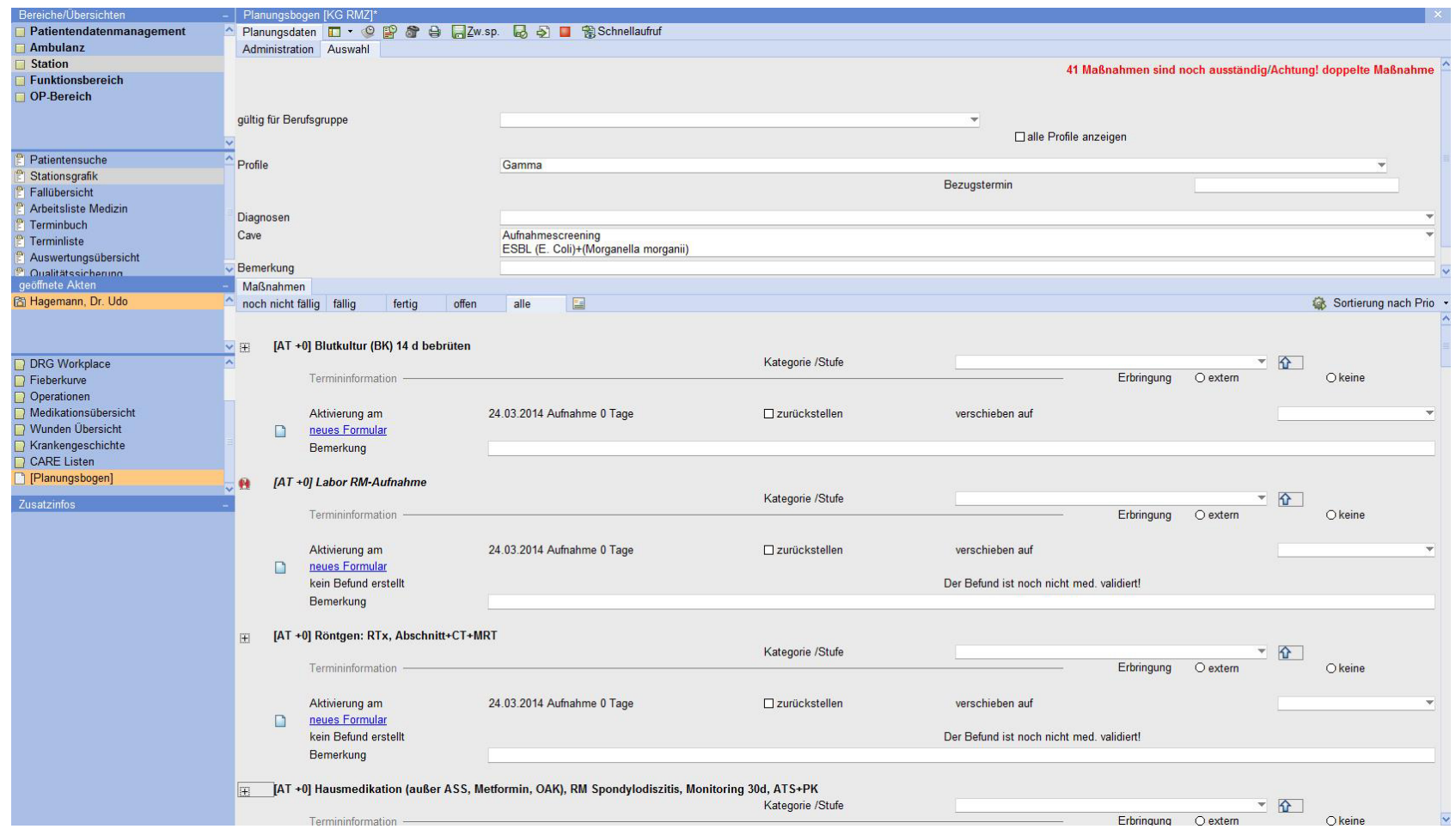

Figure 1. Page 1 clinical pathway spondylodiscitis (ORBIS, Fa. Agfa)

Table 1. Spondylodiscitis scoring system for diagnosis and therapy control using SponDT ${ }^{[15]}$

\begin{tabular}{lllll}
\hline Score value & $\mathbf{0}$ & $\mathbf{1}$ & $\mathbf{2}$ & $\mathbf{3}$ \\
\hline CRP (mg/dl) & $<10$ & $11-50$ & $51-150$ & $>150$ \\
Pain (NRS) & $<3$ & $3-5$ & $6-8$ & $>8$ \\
MRI & none/residuals & discitis & spondylodiscitis & spondylodiscitis with abcess \\
\hline
\end{tabular}

Note. NRS: numeric rating scale

Table 2. Spondylodiscitis severity code $(\mathrm{SSC})^{[15]}$

\begin{tabular}{cccc}
\hline SSC & SponDT & Neurological deficit? & Destruction? \\
\hline Grade 1 & $<3$ & No & No \\
Grade 2 & $3-6$ & No & Yes \\
Grade 3 & $>4$ & Yes & \\
\hline
\end{tabular}

Grades of severity were determined according to the SponDT score value and the SSC. The classification of severity resulted in respective therapies, such as non-operative or minimal invasive internal dorsal fixation in grade one, two-stage ventral repair of thoracic or lumbar spine in case of instability or failure of fusion in grade 2, and the spinal decompression with early ventral repair in grade 3 (see Table 2).

Statistics were done by the Kruskal-Wallis test as a statistical test for differences in the central tendency of rank data with more than 2 groups. Paired comparisons were performed using Tukey's honestly significant difference (HSD) test. For the questions of frequency, the test was performed by Monte Carlo exact test. The correlation questions were answered by Cramer's $\mathrm{V}$ as a measure of the relationship between two discrete variables.

A positive ethical approval was provided by the University of Jena.

\section{Results}

From 01/01/2012 to 12/31/2013, 42 patients with spondylodiscitis underwent surgery. Of these, 32 patients could be included in our prospective study, 17 were treated according to an electronic clinical pathway. Ten patients were excluded due to either their transfer to or from another facility or nec- 
essary treatment of co-morbidities. Nine of a total of 14 male patients and 8 of 18 female patients were treated within the pathway group. The average age was 65.9 years. Patients of the pathway group were 65.7 years on average. There were no differences in the prevalence of comorbidities. For example there were 3 patients with Diabetes mellitus in each group. It took 48.3 days from the first symptom of spondylodiscitis to hospitalisation, for the later pathway patients even medially 51.9 days.

Sixty-four percent of all patients had no previous spondylodiscitis-specific treatment at the time of admission. The duration of stay differed significantly between pathway treatment (17.2 days) and 26.0 days without pathway (see Figure 2).

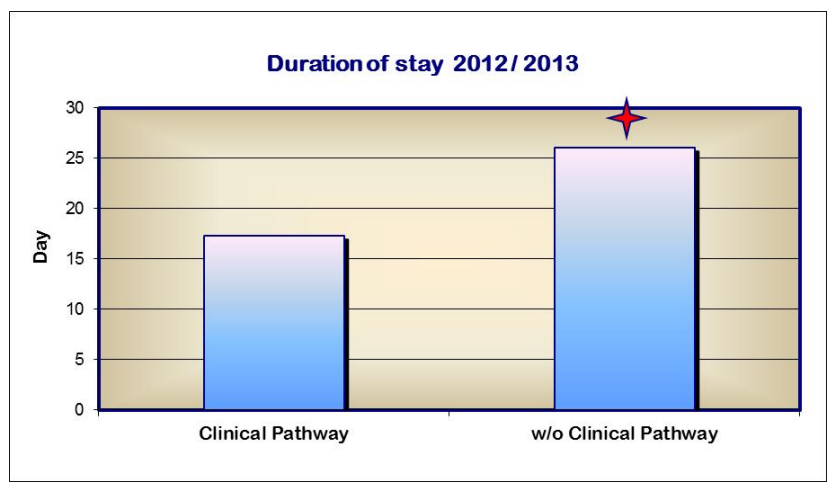

Figure 2. Duration of stay by subgroups $\left({ }^{*}=p<.05\right)$

Despite thorough diagnostics by means of laboratory testing, biopsy, CT- and MRI scans, no origin of spondylodiscitis could be found in $58.1 \%$ of all cases.

A previous sepsis was causative in $19.4 \%$ of the cases, foregone spine surgery in $16.1 \%$, vertebral body fracture in $3.2 \%$ and systemic diseases in $3.2 \%$. Predominant germs were Staphylococcus aureus (18.8\%), E.coli (12.5\%) and Staphylococcus epidermidis $(9.4 \%)$. Other infectious agents were found in $12.5 \%$ and Methicillin-resistant Staphylococcus aureus (MRSA) in 3.1\%. Despite a CT-guided or intraoperative biopsy- and/or blood culture rate of $100 \%$, there was no proof of germs histological results in $43.8 \%$. All patients received a calculated or resistogram-adjusted antibiotic therapy. Clindamycin was chosen in $43.3 \%$, ciprofloxacin in $20.0 \%$, linezolid in $3.3 \%$ other antibiotics in $26.7 \%$ and multiple combinations with clindamycin in 6.7\%. Application was made at first intravenously and after decrease of inflammatory parameters per os. The most frequent localisation of spondylodiscitis was the lumbar spine in 22 cases, the thoracic spine was affected in 10 cases and the cervical spine in 3 cases. Furthermore there were 3 patients with a multilocular spondylodiscitis.
In the period of stay there were no differences with regard to the extent of documentation, frequency of blood cultures testing or intraoperative biopsies. Also the moment of initiating further rehabilitative treatment was not significantly different. The number of laboratory tests in the pathway group was 7.2 examinations per stay, according to the requirements of the planning sheet. Thus, there were significantly fewer laboratory tests compared to the group without pathway (see Figure 3).

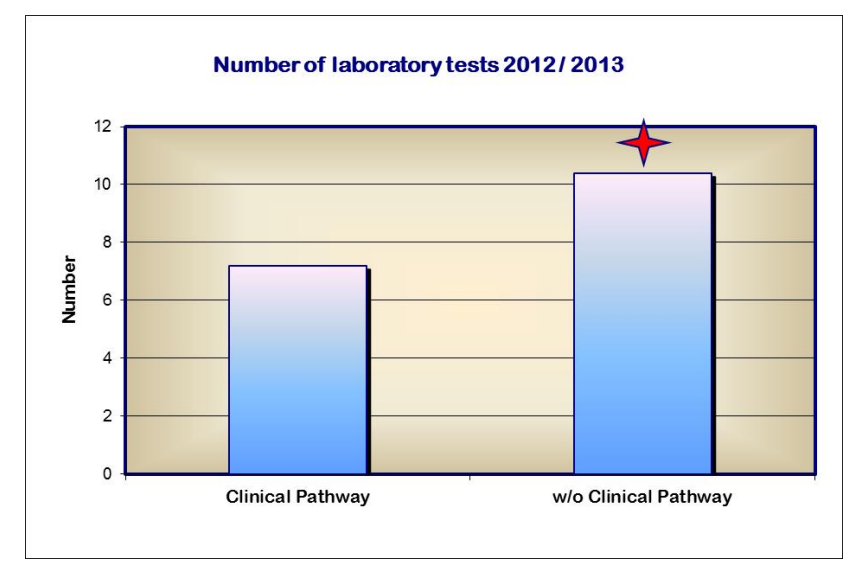

Figure 3. Frequency of lab testing by subgroups $(*=p<.05)$

The subjective pain level or the course of inflammatory markers (C-reactive protein [CRP], white blood count) showed no difference between the two groups. The subjective pain level (NRS) decreased from 6.6 on admission to 3.7 at discharge. The CRP dropped from $118.6 \mathrm{mg} / \mathrm{dl}$ to $30.1 \mathrm{mg} / \mathrm{dl}$. It cannot be assumed that pathway patients had been in a better state of health, since the SponDT as a parameter for the course of spondylodiscitis was not different, the pathway patients would have showed even higher values (see Figure 4). Furthermore, the ASA-classification was identical in both groups (2.4). Four patients of the non-pathway group did require intensive care after surgery.

The pathway patients underwent surgery 3.4 days after admission, control group patients after 8.8 days. Thirty patients underwent a dorsal stabilization with an internal fixator. In case of neurological symptoms, which were present in 3 pathway patients and 4 non-pathway patients, we additionally performed a decompression. Two patients, whose cervical spine was affected, initially underwent a ventral approach. Due to instability 7 patients received a two-stage dorso-ventral surgery. In case of a second ventral stabilisation, the point of time varied between 31.5 and 37.5 days. Seventy-five percent of the patients were treated according to severity grade 1 and $25 \%$ according to grade 2 . 
Within the cost-effectiveness analysis the following types of costs were compared:

- personnel expenses for medical staff (physicians and nurses);

- employees of medical and functional service;

- material costs for drugs, implants, other medical requirements;

- personnel and non-personnel costs of the medical in- frastructure (e.g. maintenance and repair, nursing management, pharmacy);

- non-medical infrastructure (e.g. building expenses, accommodation and energy costs, costs for insurances and administration).

The group of pathway patients showed a significant cost reduction in the area of personnel expenses (see Figure 5).
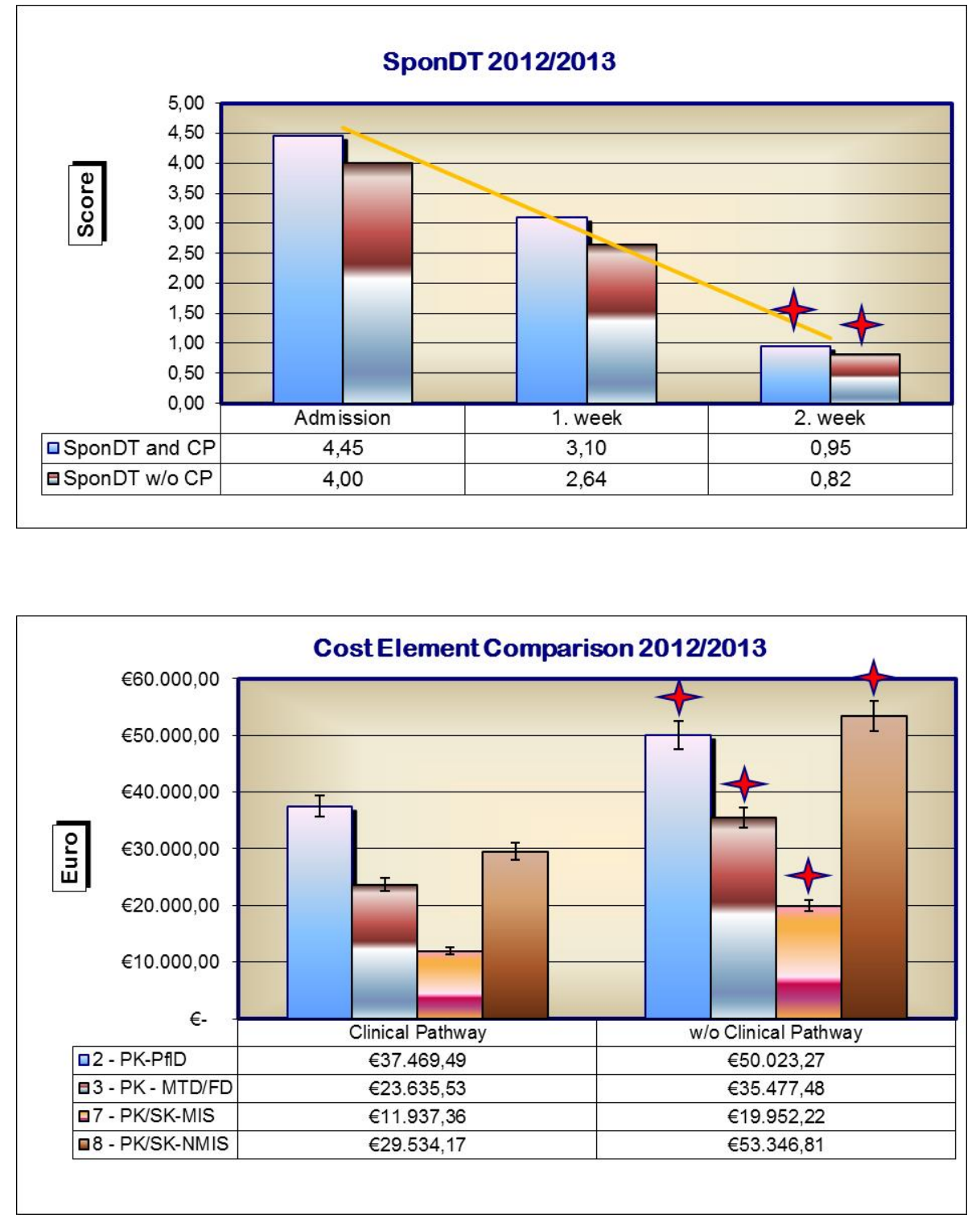

Figure 4. SponDT as parameter for the course of spondylodiscitis by subgroups $\left({ }^{*}=p<.05\right)$
Figure 5. Cost element comparison by subgroups $\left({ }^{*}=p\right.$ $<.05)$

2 - PK-PFLD: medical staff costs; 3 - PK-MTD/FD: personnel costs of medical and functional service; 7 - PK/SK-MIS: personnel and material costs of medical infrastructure; 8 - PK/SK-NMIS: personnel and material costs not medical infrastructure
Moreover, there were significantly higher costs for anaesthesiological services and laboratory testing as well as additional diagnostics when treated without pathway (see Figure 6).

From the economic point of view it remains to be said, that a treatment of spondylodiscitis using an IT-based pathway results in a total cost savings of $11,529 €$. Without pathway the cost savings is reduced to $8,705 €$. The economic condiPublished by Sciedu Press tion and increase of quality is calculated by the Incremental Cost-Effectiveness Ratio (ICER) based on clinical parameters. This is an important parameter for the cost-analysis results, which define the differences in expenses and outcomes of both alternatives. In this analysis non-monetary parameters, such as the duration of stay and subjective pain perception, reflect a positive value when treated according to the pathway. 
Figure 6. Cost center comparison by subgroups

$\left(^{*}=p<.05\right)$

\section{Cost Center Comparison 2012/2013}

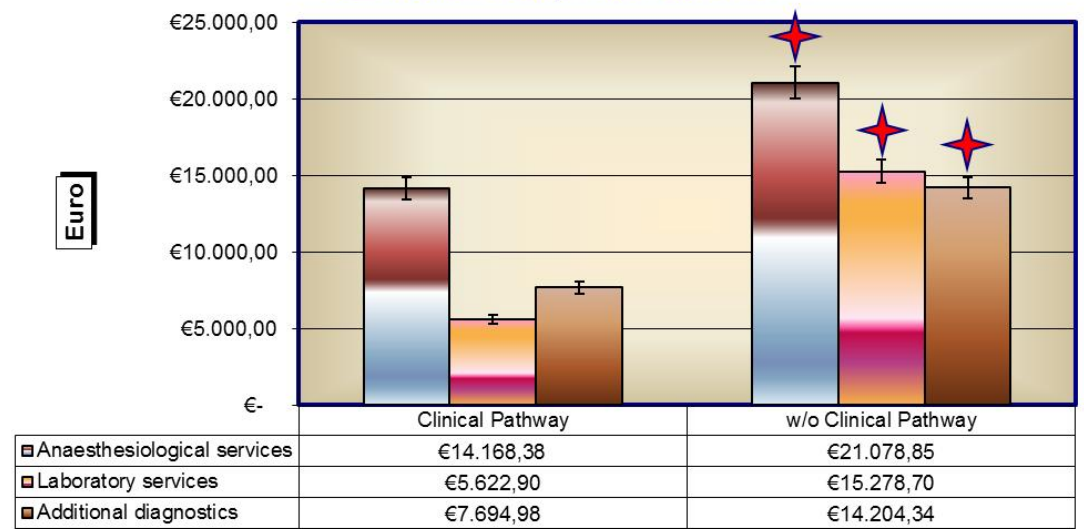

\section{Discussion}

The implementation of IT-based pathways for the surgical therapy of spondylodiscitis has been widely accepted among nurses and physicians and is now established as a common tool in the medical care routine. ${ }^{[4]}$ However, Germanbased studies are limited in quantity, compared to the AngloAmerican region and the effect of IT-based pathways on process and treatment quality remains inadequate in literature. ${ }^{[22]}$ Optimized treatment quality using scientificallyproven clinical pathways remains scarce, since most studies concentrate on economic aspects, resulting in cost-reductive pathways for both simple and complex procedures. ${ }^{[6,23-25]}$ Clinical pathways are more frequently established for standardised treatment regimens. ${ }^{[19]}$ The complex surgical treatment of spondylodiscitis is often based on certain treatment strategies, which are very variable. ${ }^{[15,24,26]}$ The main focus of this study was the implementation of an IT-based pathway for the surgical treatment of spondylodicitis including the analysis of quality and economic aspects.

For the complex therapy of spondylodiscitis, consisting of diagnosis, surgery, antibiotic treatment, regular follow-ups and physiotherapeutic measures, a structured approach is advisable. ${ }^{[24,25]}$ Often the clinical picture of spondylodiscitis is quite heterogeneous and the patients impairment disparate, even with symptoms of paraplegia. ${ }^{[27]}$ For this reason three grades of severity were determined based on current scientific insights and with the help of the SponDT, in preparation of the IT-based pathway implementation. These three severity grades are represented by separate pathways, each recommending a differentiated surgical approach. Since the former classification of severity already gave explicit instructions, a further increase of treatment quality by the implementation of pathways was not anticipated. ${ }^{[15]}$

All patients with spondylodiscitis underwent a biopsy and antibiotic treatment according to resistogram, if available, with close documentation of all measures. ${ }^{[28]}$ A shorter duration of stay and less laboratory analyses for the pathway patients lead to cost reduction without a lower quality of healthcare. The subjective pain perception was unchanged. Also, the more frequent intensive medical care in the comparison group, despite equal American Society of Anestesiologists (ASA)-classified patients, indicates an improvement with use of the pathway. ${ }^{[29,30]}$ The optimization of treatment is also reflected by the accelerated preoperative diagnostics. IT-based pathways also allow the automatic recording of all relevant treatment parameters. ${ }^{[2,31,32]}$ Although they offer obvious advantages, IT-based pathways are only reluctantly accepted for daily routine. Our own experience shows the necessity of a high level of cooperation and understanding between software developers and medical staff. ${ }^{[6,19]}$

From the economic point of view a hospital needs to operate cost-effectively. A general calculation of costs or proceeds based on the number of cases is not helpful, since every case is brought to account differently, which has been considered by this study. Longer durations of stay lead to distinctly higher personnel costs, which cannot be entirely taken into account by the diagnosis related groups (DRG) reimbursement system. The same circumstance applies to additional laboratory testing and diagnostic measures. This shows the economic advantage of electronic-based pathways, which enable a sufficient evaluation and optimization of operational processes. $^{[6,19]}$

In this study the ICER was positive for the level of pain, the documentation of treatment, and the duration of stay for the pathway group. The higher the ICER, the more efficient the alternative treatment compared to standard therapy. ${ }^{[33]}$ Nevertheless, the statement of a study should not stem from an ICER-value alone, but also be seen in the context of other 
evaluative methods of health economy such the cost-costor cost-efficiency-analysis mentioned above. ${ }^{[34]}$ Even so, this study shows the advantage of IT-based clinical pathways, which are eligible for routine use and are established as clinical and administrative management tools. ${ }^{[6,19]}$ It has to be noted that personnel and temporal expenditures for the pathway implementation itself has not been considered. ${ }^{[35]}$

Because of the inhomogeneous patient cohort and the large treatment variance there are no coherent therapy guidelines. The current opinion of treating spondylodiscitis is the immobilization of the affected spinal section and antibiotic therapy. Occasionally a standardized treatment is suggested but there is a lack of prospective randomized controlled trials and the evidence level of current treatment recommendations remains low. ${ }^{[9,14,15]}$ Our aim was to establish a manageable standard of care, which combines the advantages of several own concepts, considers economic demands of hospital treatment and takes the current treatment opinion into account. The latter vary greatly depending on the extent of the disease..$^{[9,14,15]}$

An only conservative treatment is possible, in higher levels of severity it should be reserved to high-risk patients. ${ }^{[9,14,15]}$ Relevant literature shows that surgically treated patients can expect a better quality of life and a higher level of patient satisfaction since they pass through a shorter period of immobilisation and hospitalisation ${ }^{[14,15]}$ and state a lower level of pain. For these reasons a surgical treatment of spondylodiscitis should be favoured. ${ }^{[15]}$

A ventral debridement of the affected segments and their reconstruction was the predominant surgical treatment suggestion for spondylodiscitis. Today also dorso-ventral or only dorsal procedures are established. ${ }^{[12,13]}$ Hence, for severity grade 1 spondylodiscitis without initial bone destruction an only dorsal stabilisation is recommended.

An additional ventral stabilisation should be considered in cases of remarkable bone defects or progressive segmental kyphosis according to severity grade $2 .{ }^{[15]}$ This is the most common form of therapy, since osteolytic destruction of the vertebral bodies is often found in spondylodiscitis. But a dorso-ventral approach should not be seen as the standalone procedure, due to its higher invasiveness, except for the cervical spine. Furthermore there is a higher risk of osseous loosening of the ventral instrumentation in osteoporotic bones. ${ }^{[8,14,15]}$ With the advance of the technical development of ventral stabilisation procedures, the implantation of extraneous materials such as titanium cages or PEEK prevailed. ${ }^{[8,15,24]}$ We observed this development in our own patient collective, so now expandable titanium cages are more frequently used than bone grafts.
For the treatment of severity grade 3 spinal decompression is the focus of therapy. Besides an immediate surgical therapy, a swift further treatment in a centre for paraplegia is of decisive importance for the neurologically impaired patient. ${ }^{[15,27,28]}$ The following complex secondary surgical treatment is recommended within a standardized clinical pathway. ${ }^{[15]}$

The recommended antibiotic therapy is diverse in literature. Ground-breaking studies underline the good permeation of bone and intervertebral discs. Depending on microbiological analyses mainly fluoroquinolones, lincosamides and nitroimidazoles are recommended, often combined. ${ }^{[7,9,28]}$ For the avoidance of biofilm and problem germs like MRSA and vancomycin-resistant enterococci (VRE) combinations of daptomycin and rifampicin or teicoplanin and fosfomycin are suggested. ${ }^{[9]}$ The recommended duration of antibiotic therapy varies between 2 and 12 weeks. ${ }^{[28]}$

The treatment of spondylodiscitis based on clinical pathways can be seen as common consensus with optimal use of resources. By the standardisation of essential treatment steps the quality and documentation of therapy can be increased significantly. ${ }^{[6]}$

The SponDT is useful for diagnosing and following-up spondylodiscitis. Together with the SSC it can be implemented in an IT-based clinical pathway.

\section{Conclusions}

Clinical pathways are a multi-professional consensus of workflow and documentation when treating a particular disease. As a clinical and administrative management tool it enables the optimal utilization of resources and defines responsibilities. An IT-based form can be implemented in continuation of already existing treatment principles. The previous process and result quality remains unaffected. An economization of the treatment process can be achieved as well as a complete and legally safe documentation in the patient's electronic health record.

Moreover, transparency is improved, which facilitates the initial training of new staff members, especially in hospitals with a high turnover of employees. Since IT-based pathways are an easy and practical tool for the evaluation of quality and economic efficiency, potential for improvement becomes apparent at an early stage. For this reason, hospitals should implement IT-based clinical pathways within the hospital information system to optimize treatment processes.

\section{CONFLicts OF INTEREST Disclosure}

The authors declare they have no conflicts of interest. 


\section{REFERENCES}

[1] Deneckere S, Euwema M, Lodewijckx C, et al. Better interprofessional teamwork, higher level of organized care, and lower risk of burnout in acute health care teams using care pathways: a cluster randomized controlled trial. Med Care. 2013 Jan; 51(1): 99-107. PMid: 23132203. http://dx.doi.org/10.1097/MLR. 0b013e3 182763312

[2] Schwarzbach M, Ronellenfitsch U. Klinikpfade in der Chirurgie. Ein Instrument für den Routinebetrieb [Clinical pathways in surgery. An instrument for routine procedure]? Dtsch Arztebl. 2008; 105(47): 2512-2516.

[3] Hyde E, Murphy B. Computerized clinical pathways (care plans): piloting a strategy to enhance quality patient care. Clin Nurse Spec. 2012 Sep-Oct; 26(5): 277-282. PMid: 22903208. http: //dx.doi.org/10.1097/NUR.0b013e31825aebc1

[4] Schuld J, Richetr S, Folz J, et al. Einfluss IT-gestützter Behandlungspfade auf die Patientenzufriedenheit an einer chirurgischen Universitätsklinik [Influence of IT-supported clinical pathways on patient satisfaction at a surgical department of a university hospital]. Dtsch Med Wochenschr. 2008; 133: 1235-1239. PMid: 18509799. http://dx.doi.org/10.1055/s-2008-1077245

[5] Napolitano LM. Standardization of perioperative management: clinical pathways. Surg Clin North Am. 2005; 85(6): 1321-1327. PMid: 16326212. http://dx.doi.org/10.1016/j.suc. 2005. 10.011

[6] Homagk L, Deml O, Hofmann GO. Der IT-gestützte Behandlungspfad als Routinearbeitsinstrument in der Unfallchirurgie [IT-based clinical pathway as a routine tool in trauma surgery]. Unfallchirurg. 2012 Dec; 115(12): 1076-1082. PMid: 21779899. http://dx.doi .org/10.1007/s00113-011-1996-8

[7] Lehner B, Akbar M, Rehnitz C, et al. Standards der mikrobiologische Diagnostik der Spondylodiszitis [Standards of microbiological diagnostics of spondylodiscitis]. Orthopade. 2012; 41(9): 702-710. PMid: 22945398. http://dx.doi.org/10.1007/s00132-012 $-1914-y$

[8] Mückley T, Kirschner M, Hierholzer C, et al. Spondylitis - Spondylodiszitis: neue Therapiekonzepte. Trauma Berufskrankh. 2003; 5(suppl 2): 296-304. http://dx.doi.org/10.1007/s10039-0 02-0660-5

[9] Sobottke R, Seifert H, Fätkenheuer G, et al. Current diagnosis and treatment of spondylodiscitis. Dtsch Arztebl Int. 2008 Mar; 105(10): 181-7. PMid: 19629222.

[10] Vorbeck F, Morscher M, Ba-Ssalamah A, et al. Infektiöse Spondylitis beim Erwachsenen. Radiologe. 1996; 36: 795-804. PMid: 9036417 http://dx.doi.org/10.1007/s001170050142

[11] Wikström M, Rilinger N, Vogel J, et al. Radiologische Diagnostik der infektiösen Spondylitis. Röntgenpraxis. 1996; 49: 79-84. PMid: 8677460 .

[12] Jensen AG, Espersen F, Skinhøj P, et al. Bacteremic Staphylococcus aureus Spondylitis. Arch Intern Med. 1998; 158(9): 509-517. http://dx.doi.org/10.1001/archinte.158.5.509

[13] Gouliouris T, Aliyu SH, Brown NM. Spondylodiscitis: update on diagnosis and management. J Antimicrob Chemother. 2010; 65: 11-24 PMid: 20876624. http://dx.doi.org/10.1093/jac/dkq303

[14] Colmenero JD, Jiménez-Mejías ME, Sánchez-Lora FJ, et al. Pyogenic, tuberculous, and brucellar vertebral osteomyelitis: a descriptive and comparative study of 219 cases. Annals of the Rheumatic Diseases. 1997; 56: 709-715. PMid: 9496149. http://dx.doi.o rg/10.1136/ard.56.12.709

[15] Homagk L, Homagk N, Klauss JR, et al. Spondylodiscitis severity code: scoring system for the classification and treatment of non- specific spondylodiscitis. Eur Spine J. 2015 Apr 21. [Epub ahead of print]. PMid: 25895880.

[16] Mörk S, Kothe R, Ulrich C. Infektionen der Wirbelsäule [Infections of the spine]. Orthopädie \& Unfallchirurgie. 2011; 6: 423-444. http://dx.doi.org/10.1055/s-0030-1256880

[17] Verdú-López F, Vanaclocha-Vanaclocha V, Gozalbes-Esterelles L, et al. Minimally invasive spine surgery in spinal infections. J Neurosurg Sci. 2014 Jun; 58(2): 45-56. PMid: 24819481.

[18] Murata Y, Kanaya K, Wada H, et al. Clinical outcome of percutaneous drainage for spondylodiscitis. J Neurol Surg A Cent Eur Neurosurg. 2014 Jan; 75(1): 7-11. http: //dx.doi .org/10.1055/s-0033-1 334490

[19] Homagk L, Wiesner I, Hofmann GO, et al. Sind IT-gestützte Behandlungspfade der Papierform überlegen [Are IT-based clinical pathways superior to hard-copy form]? Zentralbl Chir. 2013; 138: 64-69. PMid: 21370223. http://dx.doi.org/10.1055/s-0030-1262608

[20] Leidl R. Kritische Bewertung von gesundheitsökonomischen Studien [Critical review of health economic studies]. In Kunz R, Ollenschläger G, Raspe H (Hrsg.). Lehrbuch Evidenzbasierte Medizin in Klinik und Praxis., Deutscher Ärzte-Verlag GmbH, Köln, S. 2007; 203-216. PMid: 18030945.

[21] Busse R. Gesundheitsökonomie - Ziele, Methoden und Relevanz [Health Economics - objectives, methodology and relevance]. Bundesgesundeitsblatt - Gesundheitsforschung - Gesundheitsschutz. 2006; 49: 3-10.

[22] Ronellenfitsch U, Schwarzbach M. Klinisches Prozessmanagement - Klinische Pfade in der Chirurgie: Evidenz und Potenzial [Clinical Process Management - Clinical pathways in surgery: Evidence and Potential]. Zentralbl Chir. 2010; 135: 99-101. PMid: 20672434. http://dx.doi.org/10.1055/s-0030-1253309

[23] Dowsey MM, Kilgour ML, Santamaria NM, et al. Clinical pathways in hip and knee arthroplasty: a prospective randomised controlled study. Med J Aust. 1999; 170: 59-62. PMid: 10026684.

[24] Akbar M, Lehner B, Doustdar S, et al. Pyogenic spondylodiscitis of the thoracic and lumbar spine : a new classification and guide for surgical decision-making. Orthopade. $2011 \mathrm{Jul}$; 40(7): 614-23. PMid: 21451996. http://dx.doi.org/10.1007/s00132-011 $-1742-5$

[25] Stephen AE, Berger DL. Shortened length of stay and hospital cost reduction with implementation of an accelerated clinical care pathway after elective colon resection. Surgery. 2003; 133: 277-82. PMid: 12660639. http://dx.doi.org/10.1067/msy. 2003.19

[26] Quack V, Hermann I, Rath B, et al. Current treatment strategies for spondylodiscitis in surgical clinics in Germany. Z Orthop Unfall 2014 Dec; 152(6): 577-83. PMid: 25531518.

[27] Keil M, Szczerba L, Kraus G, et al. Therapy of septic paraplegia. Orthopade. 2012 Sep; 41(9): 742-8. PMid: 22825055. http: //dx.doi.org/10.1007/s00132-012-1918-7

[28] Marmelstein D, Homagk N, Hofmann GO, et al. Adjuvant systemic antibiotic therapy for surgically treated spondylodiscitis. Z Orthop Unfall. 2015 Apr; 153(2): 165-70. PMid: 25874395.

[29] Rosamond W, Flegal K, Furie K, et al. Heart disease and stroke statistics - 2008 update: a report from the American Heart Association Statistics Committee and Stroke Statistics Subcommittee. Circulation. 2008; 117(4): e25-146. PMid: 18086926. http: //dx.doi.org/10.1161/CIRCULATIONAHA.107.187998

[30] Saklad M. Grading of patients for surgical procedure. Anesthesiology. 1941; 2(3): 281-284. http://dx.doi.org/10.1097/00000 542-194105000-00004

[31] Deneckere S, Euwema M, Lodewijckx C, et al. Better interprofessional teamwork, higher level of organized care, and lower risk of burnout in acute health care teams using care pathways: a cluster 
randomized controlled trial. Med Care. 2013 Jan; 51(1): 99-107. PMid: 23132203. http://dx.doi.org/10.1097/MLR.0b013e3 182763312

[32] Hyde E, Murphy B. Computerized clinical pathways (care plans): piloting a strategy to enhance quality patient care. Clin Nurse Spec. 2012 Sep-Oct; 26(5): 277-82. PMid: 22903208. http://dx.doi.o $\mathrm{rg} / 10.1097 / \mathrm{NUR}$. 0b013e31825aebc1

[33] Schlander M. Was genau ist eigentlich eine ICER [What exactly is an ICER]? Der Kassenarzt Nr. 2007; 9: 56-57.

[34] Parker SL, Adogwa O, Bydon A, et al. Cost-effectiveness of min- imally invasive versus open transforaminal lumbar interbody fusion for degenerative spondylolisthesis associated low-back and leg pain over two years. World Neurosurg. 2012 Jul; 78(1-2): 178-184. PMid: 22120269. http://dx.doi.org/10.1016/j. wneu. 2011 .09 .013

[35] Krummenauer F, Guenther KP, Kirschner S. Cost effectiveness of total knee arthroplasty from a health care providers' perspective before and after introduction of an interdisciplinary clinical pathway-is investment always improvement? BMC Health Serv Res. 2011 Dec 14; 11(1): 1-11. PMid: 22168149. http://dx.doi.org/10.1186 /1472-6963-11-338 